\title{
Changes in the suprachiasmatic nucleus during aging: implications for biological rhythms
}

\author{
Rovena C. G. J. Engelberth, André L. Bezerra de Pontes, Felipe Porto Fiuza, Kayo D. de Azevedo \\ Silva, Nayra da S. Resende, Carolina Virgínia de M. Azevedo, Miriam S. M. O. Costa, Judney \\ C. Cavalcante, Expedito S. Nascimento Jr., Elaine Cristina Gavioli, and Jeferson S. Cavalcante \\ Universidade Federal do Rio Grande do Norte, Natal, RN, Brazil
}

\begin{abstract}
Animals have neural structures that allow them to anticipate environmental changes and then regulate physiological and behavioral functions in response to these alterations. The suprachiasmatic nucleus of the hypothalamus (SCN) is the main circadian pacemaker in many mammalian species. This structure synchronizes the biological rhythm based on photic information that is transmitted to the SCN through the retinohypothalamic tract. The aging process changes the structural complexity of the nervous system, from individual nerve cells to global changes, including the atrophy of total gray matter. Aged animals show internal time disruptions caused by morphological and neurochemical changes in SCN components. The effects of aging on circadian rhythm range from effects on simple physiological functions to effects on complex cognitive performance, including many psychiatric disorders that influence the well-being of the elderly. In this review, we summarize the effects of aging on morphological, neurochemical, and circadian rhythmic functions coordinated by the main circadian pacemaker, the SCN. Keywords: suprachiasmatic nucleus, aging, morphological and neurochemical changes, circadian rhythms.
\end{abstract}

Received 07 May 2013; received in revised form 03 September 2013; accepted 06 October 2013. Available online 23 December 2013.

\section{The suprachiasmatic nucleus}

Environmental cues strongly influence living organisms, and the light/dark cycle is considered the most influential aspect of the regulation of rhythmic behavior (Dibner, Schibler \& Albrecht, 2010). In mammals, periodic changes in the environment are recognized by an endogenous circadian clock. During evolution, organisms have developed numerous strategies to maintain an appropriate internal temporal order in response to alterations in the ecological niche (Hut \& Beersma, 2011). Animals have neural

Rovena C. G. J. Engelberth, André L. Bezerra de Pontes, Felipe Porto Fiuza, Kayo D. de Azevedo Silva, Carolina Virgínia de M. Azevedo, and Jeferson S. Cavalcante, Laboratory of Neurochemical Studies, Physiology Department, Biosciences Center, Federal University of Rio Grande do Norte, Natal, RN, Brazil. Nayra da S. Resende, Miriam S. M. O. Costa, Judney C. Cavalcante, and Expedito S. Nascimento Jr., Laboratory of Neuroanatomy, Morphology Department, Biosciences Center, Federal University of Rio Grande do Norte, Natal, RN, Brazil. Elaine Cristina Gavioli, Behavioral Pharmacology Laboratory, Department of Biophysics and Pharmacology, Federal University of Rio Grande do Norte, Natal, RN, Brazil. Correspondence regarding this article should be directed to: Jeferson de Souza Cavalcante, Laboratory of Neurochemical Studies, Physiology Department, Biosciences Center, Federal University of Rio Grande do Norte, Natal, RN, 59072-970, Brazil. Phone: +55 843215 3409. Fax: +55 8432119206. E-mail: jefsc@uol.com.br structures that allow them to anticipate information about cyclical environmental changes and optimally adapt to new environmental conditions (Figure 1); thus, these characteristics have implications for the survival of the species (Ukai \& Ueda, 2010; Menna-Barreto \& Díez-Noguera, 2011). In mammals, these structures are part of the circadian timing system (CTS; Cavalcante, Nascimento Júnior \& Costa, 2006), which includes a set of distinct structures that consist of a central pacemaker and afferent and efferent pathways. These structures are connected to behavioral effectors that are involved in generating and modulating biological rhythms (Dibner et al., 2010; Golombek \& Rosenstein, 2010; Figure 1).

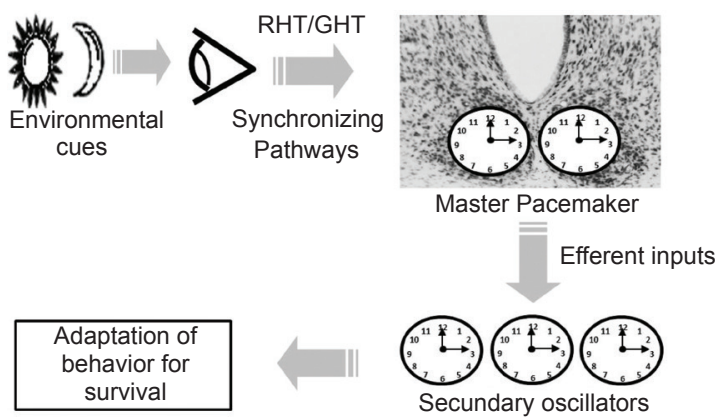

Figure 1. The circadian timing system. The control and adaptation of the biological mechanisms executed by the circadian timing system provide adequate adjustment to behavioral elaboration, thus enhancing the survival of animals. 
Among the components of this system, since the 1970s, the suprachiasmatic nucleus (SCN) of the hypothalamus has been considered the mammalian central circadian pacemaker (Hendrickson, Wagoner \& Cowan, 1972; Moore \& Lenn, 1972). Damage to the SCN results in damage to the circadian rhythms of several behavioral and physiological parameters (Moore \& Eicher, 1972). Fetal SCN transplants allow the recovery of circadian rhythms in animals that lost them as a consequence of bilateral injury of the SCN (Lehman et al., 1987; Ralph, Foster, Davis \& Menaker, 1990). Additionally, the rhythms that recovered in the animals that received the transplant had characteristics of the donor rather than the host (Ralph et al., 1990).

Although the SCN displays variations with regard to tridimensional shape, volume, density, and cell size in all species studied (Figure 2), morphologically in mice, each unilateral SCN has approximately 10,000 neurons divided into two main neuronal populations: ventral or "core" (a producer of vasoactive intestinal polypeptide [VIP]) and dorsal or "shell" (which has vasopressin [VP] as its main neurotransmitter; Abrahamson \& Moore, 2001; Morin, 2007; Mammen \& Jagota, 2011). Approximately 1,100 neurons $(\sim 10 \%)$ in the unilateral SCN express VIP in the core subdivision. Approximately 2,100 neurons $(\sim 20 \%)$ in the shell express VP (Welsh, Takahashi \& Kay, 2010). In rodents, the levels of VP and VIP show specific daily oscillations under light/ dark conditions, suggesting that they act on the rhythm of behavioral expression (Dardente et al., 2004).

The light/dark cycle is considered the strongest synchronizer of circadian rhythms (Morin \& Allen, 2006; Xu, Gu, Pumir, Garnier \& Liu, 2012). Photic information is transmitted to the SCN through the retinohypothalamic tract (RHT), which originates from melanopsincontaining retinal ganglion cells. These cells project bilaterally to the SCN (Hendrickson et al., 1972; Moore \& Lenn, 1972) and geniculohypothalamic tract (GHT), which originates in the intergeniculate leaflet and, similar to RHT, terminate at the ventrolateral portion of the SCN. A third afferent pathway to the SCN is a serotonergic projection that comes from raphe mesencephalic nuclei, mainly from the median raphe nucleus (Hay-Schmidt, Vrang, Larsen \& Mikkelsen, 2003; Pontes et al., 2010). Interestingly, some findings suggest that serotonin (5-hydroxytryptamine [5-HT]) should modulate the photic entrance to the SCN by controlling the release of glutamate from the RHT (Morin, 1999; Figure 1).

Other neurotransmitters, in addition to VIP and $\mathrm{VP}$, have been described in terminals and perikarya in the SCN, such as neuropeptide Y (NPY; Costa et al., 1998; Abrahamson \& Moore, 2001; Cavalcante, Alves, Costa, \& Britto, 2002; Pinato, Frazão, Cruz-Rizollo, Cavalcante \& Nogueira, 2009), 5-HT (Abrahamson \& Moore, 2001; Cavalcante et al., 2002; Pontes et al., 2010), glutamate (GLU; Van den Pol, 1991; de Vries, Cardozo, van der Want, Wolf \& Meijer, 1993), and $\gamma$-aminobutyric acid (GABA; Castel \& Morris, 2000; Abrahamson \& Moore, 2001).
The circadian pacemaker in the SCN is composed of multiple oscillator cells with individual electrical activity rhythms that become synchronized by synaptic coupling (Nakamura, Honma, Shirakawa \& Honma, 2001). This was initially observed in dispersed cultures of SCN neurons (Welsh, Logothetis, Meister \& Reppert, 1995) and later demonstrated in slice preparations (Nakamura et al., 2001). In the SCN, groups of cells constitute several internally coupled oscillatory subsets that can differ in resetting mechanisms because of photic and non-photic time cues (Silver \& Schwartz, 2005). Studies have shown a functional subdivision within the $\mathrm{SCN}$. In fact, the left and right sides of the SCN may behave differently in different experimental protocols, and they can lead to the temporal splitting of rhythmic output functions, such as locomotor activity (de la Iglesia, Meyer, Carpino \& Schwartz, 2000). In another forced desynchronization protocol, differences between the ventrolateral and dorsomedial SCN zones have been observed in rats (de la Iglesia, Cambras, Schwartz \& Díez-Noguera, 2004), providing a novel approach to understanding the tissue organization of the SCN.

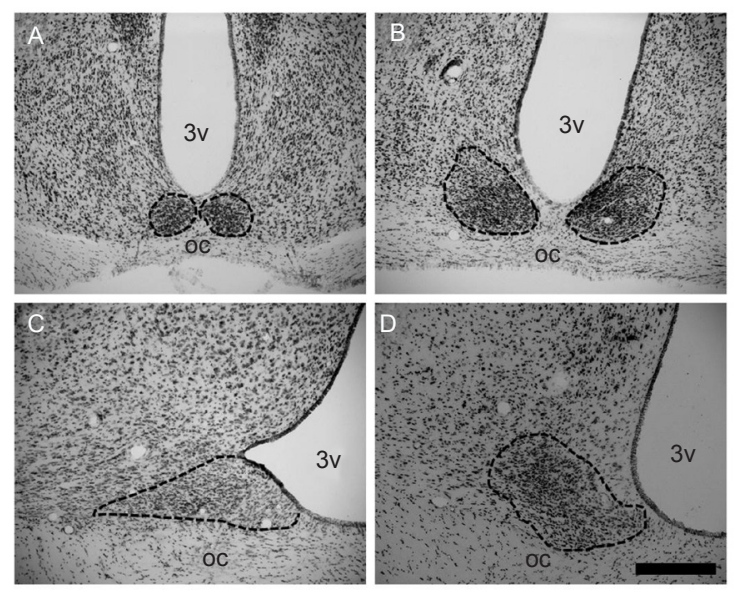

Figure 2. The suprachiasmatic nucleus. Digital images of coronal sections of Nissl staining of the suprachiasmatic nucleus that show morphological differences in four species: mouse (A), rat (B), marmoset (C), and cebus (D). 3v, third ventricle; oc, optic chiasm. Scale bar $=300 \mu \mathrm{m}$ in A and B; $150 \mu \mathrm{m}$ in $\mathrm{C}$ and D. The digital images were obtained in the Neuroanatomy Laboratory, Federal University of Rio Grande do Norte.

\section{Aging}

In human, aging is considered a multidimensional process, in which environmental factors may intensify or provide protection from natural degeneration (Schmidt, Peigneux, \& Cajochen, 2012). The large variations during an organism's lifetime are mainly influenced by environmental factors, whereas the genetic contribution is approximately $25-30 \%$. Over the years, the behavioral and biological manipulations have resulted in considerable increases in the human life expectancy (Deelen, Beekman, Capri, Franceschi \& Slagboom, 2013).

Many hypotheses have attempted to explain the mechanism of aging. A possible way to explain the aging 
process suggests an important role for mitochondrial dysfunction, which contributes to the increase in free radical species (Bishop, Lu \& Yanker, 2010). In humans, a reduction of protein expression caused by the dysfunction of mitochondrial energy metabolism contributes to the cognitive decline that is typical of old age and Alzheimer's disease (Miller, Oldham \& Geschwind, 2008). Molecular biology studies have suggested that this decrease in mitochondrial gene expression is a conserved characteristic in older organisms, from Caenorhabditis elegans to humans, in which the nervous system and muscles are particularly more susceptible to functional mitochondrial deficits (Bishop et al., 2010). Together with mitochondrial dysfunction, oxidative stress also appears to be a strong candidate that promotes alterations in older organisms (Muller, Lustgarten, Jang, Richardson \& Van Remmen, 2007). Park et al. (2009) reported that diets rich in antioxidants may decrease the expression of many genes related to the aging process in the mouse brain (Park et al., 2009), and it may minimize cognitive decline in older rats (Liu et al., 2002).

When focusing specifically on the effects of aging on the central nervous system (CNS), many morphological and neurochemical alterations during life result in several behavioral changes, such as cognitive dysfunction (Fjell \& Walhovd, 2010). Aging alters the structural complexity of the CNS, resulting in decreased soma size, decreased dendrites and dendritic spines in individual neurons (Duan et al., 2003), alterations in neurotransmitter receptors (Hof \& Morrison, 2004), and changes in electrophysiological properties (Chang, Rosene, Killiany, Mangiamele \& Luebke, 2005). Other general changes are also reported in the CNS, including substantial atrophy of total gray matter (Oh, Madison, Velleneuve, Markley \& Jagust, 2013), and activation of the ipsilateral and contralateral prefrontal cortex appears to be activated in young individuals (Persson et al., 2004), suggesting a compensatory mechanism of the CNS in response to the aging process (Figure 3 ).

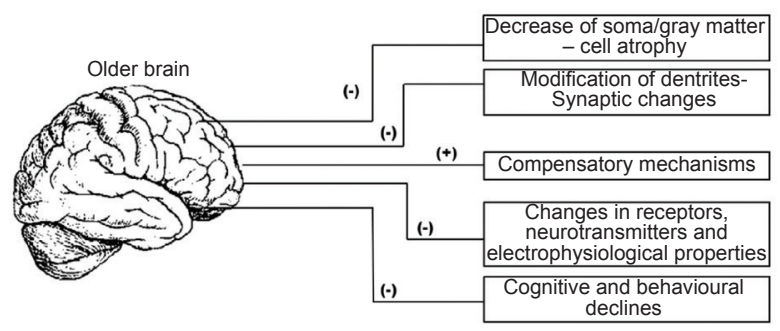

Figure 3. Alterations in the older brain. Several changes that are observed in the nervous system of elderly animals are deleterious (-) and result in physiological and behavioral alterations, thus impairing survival or welfare during aging. Mechanisms may have been developed by the CNS to mitigate these deleterious effects (e.g., bilateral activation in elderly animals of some areas during the execution of specific tasks, thus exhibiting compensatory mechanisms $[+]$ ).
Many circuits can be interrupted by a decrease in synapses and cellular death during aging, but some areas of the CNS have differences in their vulnerability to neurodegeneration (Tomasy \& Volkow, 2012). Once many CNS areas suffer from the effects of aging, some components of the CTS may change structurally and neurochemically, thus contributing to behavioral alterations. This idea is supported by data that show changes in synchronization parameters caused by photic and non-photic stimuli in elderly animals (Duncan, 2006).

\section{The aging suprachiasmatic nucleus}

The SCN allows the organism to have an internal temporal order, thus contributing to the adequate execution of physiological and behavioral mechanisms. However, when the circadian clock in young animals is not synchronized with the environment, homeostasis is disturbed and displays some functions similar to those observed in aged animals, such as a decrease in time precision (Zhdanova et al., 2011; Davidson, Yamazaki, Arble, Menaker \& Block, 2008).

Interestingly, longevity appears to be correlated with the adequate circadian rhythm pattern exhibited by the organism. The transplantation of tissue that contained neonatal SCN tissue in old hamsters increased life span, thus restoring normal rhythms in many physiological mechanisms (Hurd \& Ralph, 1998). Additionally, the circadian rhythm in old mice was reported to be improved after they received a transplant of fetal tissues that contained the SCN in the third ventricle (Li \& Satinoff, 1998).

The effects of aging on circadian rhythm range from effects on simple physiological functions to effects on complex cognitive performance (Antoniadis, Ko, Ralph \& McDonald, 2000). Considering that aging affects biological functions regulated by the SCN, the SCN could be a primary locus for changes related to the aging process (Yamazaki et al., 2002; Figure 4).

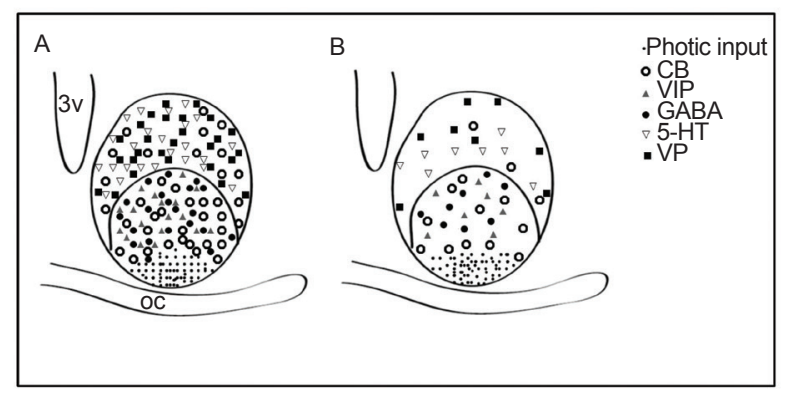

Figure 4. The aging suprachiasmatic nucleus. Many morphological and neurochemical alterations may be seen in the SCN in aged animals (B) compared with young animals (A). These changes result in a decline of biological behaviors controlled by the central circadian pacemaker, such as fragmentation on the sleep-wake cycle in elderly humans. Some neurochemical compounds decrease in the SCN in aged animals compared with young animals, such as VIP, VP, GABA, 5-HT, and CB. 3v, third ventricle; oc, optic chiasm. 


\section{Morphological modifications in the aged suprachiasmatic nucleus}

Zhang et al. (1998) reported that old animals are less sensitive to the synchronizing effects of the light/ dark cycle than young animals. However, these authors observed that the RHT pathway was morphologically unaltered in old animals, thus suggesting that these synchronization deficits could be attributable to alterations in the retina or SCN (Figure 4). Little information is available about morphological alterations in the eyes as a possible site of the effects of aging that may result in circadian changes.

Some studies have reported an abrupt decrease in the absorption of blue light within the visible spectrum in the retina in humans who were over 60 years old (Dillon, Zheng, Merriam \& Gaillard, 2004) and a small decrease in melanopsin-containing retinal ganglion cells (Kessel, Lundeman, Herbst, Andersen \& Larsen, 2010). Some consequences of the changes in photoreception on the circadian rhythm have been reported. Healthy elderly individuals without cataracts exhibit a decrease in phase-delay responses to moderate light, but they did not differ from young individuals with regard to night exposure to a monochromatic and polychromatic white light (Duffy, Zeitzer \& Czeisler, 2007; Münch et al., 2011). Molecular studies of aging in the SCN have found a significant decrease in c-fos expression induced by light in mice, rats, and hamsters (Zhang et al., 1998) and a decrease in Perl expression in mice (Kolker et al., 2003). Biello (2009) suggested that molecular changes in response to light stimuli may occur because of the decreased action of GLU on NMDA receptors during senescence.

Alterations related to aging cannot be purely explained by cellular death or atrophy of the SCN. Some studies have reported contradictory results with regard to the decrease in neuronal cells and neuroglia in the SCN in rats, particularly when comparing male and female animals (Madeira, Sousa, Santer, Paula-Barbosa \& Gundersen, 1995; Tsukahara, Tanaka, Ishida, Hoshi \& Kitagawa, 2005; Roberts, Killiany \& Rosene, 2012). Post mortem studies showed that neurodegenerative processes occur in the SCN during senescence, suggesting progressive deterioration of the circadian pacemaker in the human brain during aging (Zhou \& Swaab, 1999; Hofman \& Swaab, 2006).

Madeira et al. (1996) performed a stereological study in male and female adult and aged rats and did not observe any effect of age or sex on the total number of neurons or astrocytes in the SCN. In a similar study, Tsukahara et al. (2005) reported no alterations in the total size of the SCN in rats, regardless of age and sex. However, a decrease in the number of neurons was observed in the SCN in elderly rats compared with young rats of both sexes. These authors also observed stability of the neuronal decline in adult male individuals until old age. In males, the neurodegeneration appears to occur during the adult phase. Recently, Roberts et al. (2012) confirmed the stability of neuronal decline in the SCN in adult male rhesus monkeys compared with aged male animals. Roberts et al. (2012) also found a decrease in the number of neurons in the dorsomedial and ventrolateral portions of the SCN in adult male rhesus monkeys and adult and aged females compared with young individuals. In the same study, the authors analyzed the nuclear diameter of SCN cells, observing atrophy of the nuclear size of these neurons with increasing age in monkeys of both sexes (Roberts et al., 2012). Interestingly, the effects of aging on neuroglia differed from the effects observed in neurons. These same studies reported an increase in the amount of glial fibrillary acidic protein (GFAP) expression (i.e., a marker of astrocytes) in the SCN in rats and rhesus monkeys, especially in the dorsomedial part of this nucleus (Tsukahara et al., 2005; Roberts et al., 2012).

A decrease in electrical activity in the SCN cells was also reported (Nygård, Hill, Wikstrom \& Kristensson, 2005). Nygård et al. (2005) used tissue slices from young and old mice to analyze the electrophysiological properties of the ventrolateral part of the SCN. Both young and old mice displayed significant variations in the mean firing rate between day and night. Old animals exhibited an elevated number of such silent cells during the day compared with young animals. The frequency of spontaneous inhibitory postsynaptic currents was also reduced in ventrolateral SCN neurons in old animals (Nygård et al., 2005; Farajnia et al., 2012). This reduction of the electrical activity of the cell membrane could be partially explained by age-dependent changes in the properties of the cell membrane (Farajnia et al., 2012).

\section{Neurochemical implications of the aging suprachiasmatic nucleus}

Together with the morphological alterations in the SCN induced by age, a decrease in the expression of many neurotransmitters is also observed, including VIP, VP, 5-HT, GABA, and other neurochemical compounds, such as calbindin (CB; Figure 4; Swaab, Flies \& Fisser, 1985; Harper et al., 2008; Duncan, Hester, Hopper \& Franklin, 2010).

Studies have reported different results with regard to the reduction of VIP immunoreactivity (Kawakami et al., 1997; Cayetanot, Bentivoglio \& Aujard, 2005a) and VP (Cayetanot et al., 2005a) in the SCN in rodents and nonhuman primates. A nonsignificant decrease in the total number of VP-expressing cells was observed in elderly humans (Hofman, Fliers, Goudsmith \& Swaab, 1988). However, nonhuman mammals, such as aged rodents and primates, exhibit consistent decreases in VIP expression (Kawakami et al., 1997; Cayetanot et $a l ., 2005 \mathrm{a}$ ) and VIP mRNA in the SCN (Duncan, Herron \& Hill, 2001; Kalló, Kalamatianos, Piggins \& Coen, 2004). Alterations in VP immunoreactivity were also observed in rats and nonhuman primates (Roozendaal, Van Gool, Swaab, Hoogendijk \& Mirmiran, 1987; Cayetanot et al., 2005a), which showed decreased expression. Interestingly, the reduction of VIP and 
VP expression in rats was restored in aged animals after treatment with the neurotrophin nerve growth factor (NGF; Pereira, Cardoso \& Paula-Barbora, 2005). Importantly, the reinstatement of VIP- and VPimmunoreactive fibers in the SCN in aged rats did not clearly restore the circadian rhythmic impairments induced by aging (Pereira et al., 2005).

Studies have reported substantial changes in temporal VIP and VP expression in the SCN in elderly nonhuman primates (Microcebus murinus) compared with adults (Cayetanot et al., 2005a; Aujard, Cayetanot, Bentivoglio \& Perret, 2006). Vasopressin exhibited a daily rhythm in neuron number and immunostaining in young animals, with higher peaks of VP occurring during the second part of the day. In elderly animals, VP expression was more accentuated in the early evening (Cayetanot et al., 2005a; Aujard et al., 2006). The peak VIP expression occurred during the night in adult individuals. In elderly animals, the highest VIP expression occurred at the beginning of the day (Cayetanot et al., 2005a; Aujard et al., 2006).

Vasopressin is described as a neurotransmitter involved in rhythm amplification, acting as a feedback regulator of electrical activity inside the SCN (Ingram, Terenzi, Howard \& Windle, 1998). Animal experiments have demonstrated an important role for VP derived from the $\mathrm{SCN}$ in the control of neuroendocrine day/ night rhythms, such as in the hypothalamic-pituitaryadrenal axis (Kalsbeek, Van Heerikhuize, Wortel \& Buijs, 1996; Kalsbeek et al., 2008). The remarkable correlation between the diminished presence of VP in the SCN and deterioration of sleep-wake rhythms during aging, in addition to neurodegenerative diseases and mood disorders, indicate that VP neurons significantly contribute to the rhythmic output of the SCN, even in humans (Liu et al., 2000; Zhou et al., 2001).

Vasoactive intestinal polypeptide cells innervate the SCN itself, suggesting the presence of a self-feedback loop within the SCN (Piggins \& Cutler, 2003). These cells receive a direct retinal input (Tanaka, Ichitani, Okamura, Tanaka \& Ibata, 1993; Glass, Guinn, Kaur \& Francl, 2010), and photic stimulation activates these neurons, reflected by the activation of Fos proteins (Romijn, Sluiter, Pool, Wortel \& Buijs, 1996), thus adjusting the phase of the SCN in response to zeitgebers. Consequently, a decrease or change in the time or expression of VIP may cause irregular electrical activity of SCN neurons and alterations in behavioral execution (Ingram et al., 1998; Cayetanot et al., 2005a). Vasoactive intestinal polypeptide cells receive from the SCN (Piggins \& Cutler, 2003). The decrease in the expression of VIP mRNA or product may be partially responsible for the decrease in the ability to respond to photic and non-photic stimuli reported in aged animals (Zhang et al., 1996; Duncan, 2006).

Deficits have been described in reproductive mechanisms controlled by the SCN. In old female rats, the ability of the SCN to stimulate the production of hormone waves weakens. Vasoactive intestinal polypeptide mRNA becomes arrhythmic in the SCN in middle-aged female hamsters (Krajnak, Kashon, Rosewell \& Wise, 1998; Gerhold, Katherine \& Wise, 2005), and VIP deprivation in the SCN in young female hamsters induced deficits in the release of gonadotropin releasing hormone and luteinizing hormone, thus simulating what occurs in aged female hamsters (Gerhold et al., 2005).

Alterations in the density of GABAergic terminal axons and the $\mathrm{GABA}_{\mathrm{A}} \alpha 3$ receptor subunit have been reported in the SCN in elderly mice (Palomba et al., 2008). GABA plays an important role in the regulation and synchronization of the amplitude of electrical activity in SCN neurons (Aton, Huettner, Straume \& Herzog, 2006), and it appears to act together with VIP, in which $70 \%$ of the synaptic terminals may contribute to a decrease in or inadequate signaling of VIP neurons in the SCN (Palomba et al., 2008).

In mammals, age-related changes in the serotonergic system are involved in distinct disorders, such as changes in sleep patterns, mood disorders (Meltzer et al., 1998), and neurodegenerative diseases (Benninghoff et al., 2012; Fidalgo, Ivanov \& Wood, 2013). 5-HT regulates some of the behavioral parameters of the CTS that undergo aging-related alterations, such as the circadian rhythm of wheel-running activity or phase shifts (Penev, Zee, Wallen \& Turek, 1995). 5-HT is a melatonin precursor. It has been shown that the synthesis and metabolism of 5-HT during the day is reduced in older pigeons (Garau, Aparicio, Rial, Nicolau \& Esteban, 2006), which could be related to a decrease in melatonin during aging (Hardeland, 2013). Many studies have reported changes in 5-HT receptors in the $\mathrm{SCN}$ in aged animals (Duncan \& Franklin, 2007; Duncan et al., 2010), and these alterations may influence behaviors that depend on neurotransmitter release (Garau et al., 2006). Additionally, a previous study showed that systemic administration of the $5-\mathrm{HT}_{1 \mathrm{~A}}$ receptor agonist 8-hydroxy-2-(di- $n$-propylamino)tetralin (8-OH-DPAT) mimicked non-photic phase shifts in young adult hamsters, whereas it was ineffective in old hamsters (Penev et al., 1995). These findings suggest a possible decrease in the sensitivity of the serotonergic system. Similar to what is seen in the GABA system, high 5-HT, receptor expression was found in the dorsal subdivision of the $\mathrm{SCN}$, a brain area characterized by $\mathrm{CB}$ expression (Duncan \& Franklin, 2007).

Synaptic plasticity is known to critically depend on the influx of neuronal $\mathrm{Ca}^{2+}$ and the signaling pathways mediated by this ion. The decline in the expression of calcium-binding proteins, such as $\mathrm{CB}$, renders the neurons more vulnerable to excitotoxic insults mediated by $\mathrm{Ca}^{2+}$, thus contributing to neurodegeneration (Geula et al., 2003). A decrease in the daily variation of CB immunoreactivity, the most prominent chelating protein for $\mathrm{Ca}^{2+}$, has been reported in the primate SCN (Cayetanot, Deprez \& Aujard, 2007). Calbindinimmunoreactive cells within the SCN constitute a small cluster of cells that express Fos protein in 
response to light (Silver et al., 1996). Injury of the SCN leads to the disruption of the circadian rhythm of locomotor activity (Kriegdfeld, LeSauter \& Silver, 2004). These behavioral alterations are quite similar to the locomotor activity changes observed in elderly animals (Valentinuzzi, Scarbrough, Takahashi \& Turek, 1997). Altogether, these data suggest a possible relationship between the disruption in the circadian rhythm of locomotor activity and a decrease in CBimmunoreactive cells in the SCN.

Neuropeptide $\mathrm{Y}$ is another neuropeptide that has important functions in the SCN. It is implicated in the photic (Yannielli \& Harrington, 2004) and non-photic (Biello, Janik \& Mrosovsky, 1994) regulation of this brain area. Studies have revealed changes in NPY expression and some of its receptors in various areas of the CNS in aged animals (Kuruba, Hattiangady, Parihar, Shuai \& Shetty, 2011; Veyrat-Durebex, Quirion, Ferland, Dumont \& Gaudreau, 2013), such as in cortical areas (Huh, Kim, Lee, Kim \& Ahn, 1997). However, no data have shown any changes in other components of the CTS beyond the SCN. Therefore, a wide field exists for studies on other alterations that may interfere with the precise function of the circadian clock in elaborating and regulating biological mechanisms that optimize the execution of behavior.

\section{Implications of the aging suprachiasmatic nucleus on circadian rhythm}

Changes in many basic parameters of circadian rhythm in mammals are associated with aging. These changes include alterations in the length of the circadian period and a reduction of the amplitude and duration of the phase of rhythm activity regulated by the clock (Satinoff et al., 1993; Watanabe, Shibata, \& Watanabe, 1995; Figure 5), resulting in altered responses to photic and non-photic stimuli (Brock, 1991; Duncan, 2006).
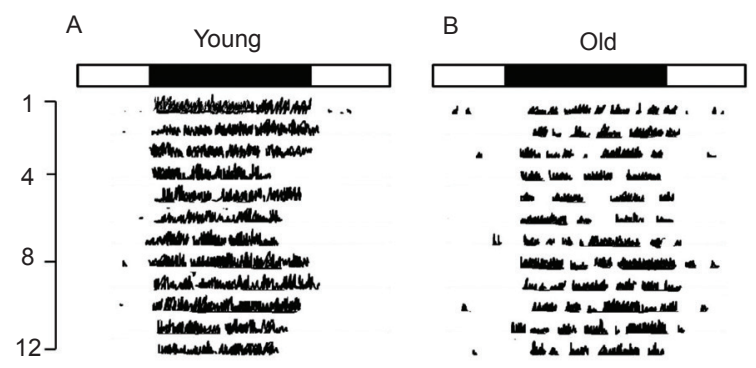

Figure 5. Hypothetical representation of activity records from a young (A) and old (B) nocturnal animal entrained to a 12 $\mathrm{h} / 12 \mathrm{~h}$ light/dark cycle. Successive days are plotted from top to bottom. One to $24 \mathrm{~h}$ periods of activity are represented on the $\mathrm{x}$-axis. The black bar indicates the dark phase of the light/ dark cycle. The old animals exhibit a fragmented rhythm with a decrease in amplitude.

A decrease in the amplitude of circadian rhythm is followed by an increase in the percentage of the ultradian component during the last week of life in mice
(Weinert \& Weinert, 1998). This decrease enhances the splitting of circadian rhythm (Morin, 1988). This loss of amplitude, together with a broadening of the period, may be attributable to weaker coupling between two or more oscillators that control circadian rhythm (Pittendrigh, 1981a). Consistent with the theory of coupled oscillators (Pittendrigh, 1981b), age-dependent differences in the phase angle between circadian rhythms and the exogenous zeitgeber might be caused by changes in period lengths or may be modified by coupling strength. Studies of the coupling strength between the circadian oscillator and zeitgeber have investigated the response of the oscillator to external stimuli. During aging, this response declines (Zhang et al., 1998). Witting, Mirmiran, Bos \& Swaab (1993) found that the amplitude of the activity rhythm during synchronization to the light/dark cycle could be increased simultaneously with the intensity of light. Therefore, the amplitude of the rhythm in older animals that are exposed to very intense light may resemble the amplitude exhibited by young animals, demonstrating a decrease in the sensitivity of cells. Aged rats and mice exhibit deficits in their photic synchronization abilities (Benloucif, Masana \& Bubocovich, 1997), with a loss in response to light pulses (Zhang et al., 1998; Benloucif et al., 1997) and non-photic stimuli (Van Reeth, Zhang, Reddy, Zee \& Turek, 1993; Duncan, 2006). Furthermore, the locomotor activity patterns of these animals show increased fragmentation, period lengthening, and resynchronization changes (Nakamura et al., 2011; Valentinuzzi et al., 1997).

A recent study reported a decline in the number of dopaminergic neurons in aged rats, which might be related to the changes seen in the circadian period of locomotor activity (Tanaka et al., 2012), circadian drinking behavior (Burwell, Whealin \& Gallagher, 1992), locomotor activity (Valentinuzzi et al., 1997), and body temperature rhythm (Weinert, 2010), all of which have a reduced amplitude in older rats.

Cayetanot, Van Someren, Perret \& Aujard (2005b) and Aujard et al. (2006) showed that 5-month-old lemurs (Microcebus murinus) that were subjected to an acceleration of seasonal cycles exhibited the same changes in locomotor pattern that are observed in chronobiologically aged animals (6-9 years of age). Additionally, aged individuals and animals with seasonal acceleration exhibited significant differences in locomotor activity compared with adults and adolescents (2-4.5 years of age). Chronobiologically elderly animals and artificially accelerated animals (2-4.5 years old; 5-9 seasonal cycles) showed a decrease in night activity and an increase in diurnal activity. This disruption of the sleep-wake cycle and activity fragmentation pattern are similar to observations in senescent humans.

In humans, healthy aging is associated with normal changes that occur in sleep architecture and patterns, such as a decrease in sleep during the night period, a decline of the deep sleep stage, and an increased frequency and duration of naps during the day, thus 
presenting a loss of amplitude and fragmentation of the activity-rest rhythm (Huang et al., 2002; Tractenberg, Singer \& Kaye, 2005). Perhaps the most characteristic sign is a phase advance of the normal circadian cycle. Therefore, elderly people have a propensity toward earlier sleep onset, accompanied by an earlier morning wake signal (Wolkove, Elkholy, Baltazan \& Palayew, 2007). There is a reduction of delta sleep (stages 3 and 4 ; the deepest and most refreshing form of sleep) that begins in middle-age, with some reports that these deeper stages are completely absent after the age of 90 (Ohayon, Carskadon, Guilleminault \& Vitiello, 2004). Similar sleep pathologies are found in the elderly, including insomnia (defined as difficulty falling or staying asleep; Monane, 1992; Reid et al., 2006) and rapideye-movement sleep behavior disorder (characterized by a loss in muscle atonia; Wolkove et al., 2007), that usually affects people older than 60 and is frequently associated with other neurodegenerative conditions such as Parkinson's disease, multiple sclerosis or Alzheimer dementia (Olso, Boeve \& Silber, 2000). An interesting study reported that healthy elderly appeared to need less sleep time physiologically (Duffy, Willson, Wang \& Czeisler, 2009). A longitudinal sleep pattern study of rhesus monkeys observed similar modifications as in humans, such as a decline in the daily activity period associated with many modifications of sleep quality and quantity (Zhdanova et al., 2011).

In the elderly, several factors possibly contribute to changes in sleep and circadian rhythm desynchronization (Cooke \& Ancoli-Israel, 2011). As discussed above, the SCN deteriorates with age (Zhou \& Swaab, 1999; Hofman \& Swaab, 2006), which may result in weaker or more disrupted circadian rhythms. Furthermore, other disturbances involved in the entrainment of the circadian rhythm of sleep may appear (Cooke \& AncoliIsrael, 2011). For example, the nocturnal secretion of endogenous melatonin gradually decreases with age (Hardeland, 2012). The reduction of melatonin in aged animals could possibly occur through insufficient environmental illumination (Mishima, Okawa, Shimizu \& Hishikawa, 2001) or a decrease in photic absorption in older animals (Zhang et al., 1996, Zhang et al., 1998). In mammals, pineal melatonin biosynthesis and release are, in turn, under the control of the SCN and largely confined to the night (Tricoire, Locatelli, Chemineau \& Malpaux, 2003). Melatonin secretion plays an important role in the sleep-wake cycle, and this decline may result in reduced sleep efficiency and an increased incidence of disturbances of the circadian rhythm of sleep (Hardeland, 2012; Hardeland, 2013).

Elderly people may have exogenous cues that are too weak to entrain to the light-dark circadian rhythm (Zhang et al., 1996; Aujard et al., 2001), thus influencing the sleep-wake rhythm. Light is one of the most powerful zeitgebers. Studies have shown that elderly patients, especially those who are institutionalized, spend too little time in daylight. This reduced level of bright light is associated with nighttime sleep fragmentation and disorders of the circadian rhythm of sleep (Shochat, Martin, Marler \& Ancoli-Israel 2000).

Changes in the circadian rhythm of activity, such as sleep, become irregular with age, leading to a decline in quality of life by inducing, among others, cognitive deficiency and emotional stress (Singletary \& Naidoo, 2011). The severe interruption of circadian rhythm is associated with an increased susceptibility to disease (Gibson, Williams \& Kriesgsfeld, 2009), which raises interest about circadian changes caused by the aging process.

\section{Acknowledgements}

The authors thank CAPES, FAPERN, and CNPq for financial support.

\section{References}

Abrahamson, E. E., \& Moore, R.Y. (2001). Suprachiasmatic nucleus in the mouse: retinal innervation, intrinsic organization and efferent projections. Brain Research, 916, 172-91.

Antoniadis, E. A., Ko, C. H., Ralph, M. R., \& McDonald, R. J. (2000). Circadian rhythms, aging and memory. Behavioural Brain Research, 114, 221-233.

Aton, S. J., Huettner, J. E., Straume, M., \& Herzog, E. D. (2006). GABA and Gi/o differentially control circadian rhythms and synchrony in clock neurons. Proceedings of the National Academy of Sciences of the United States of America, 103, 19188-19193.

Aujard, F., Cayetanot, F., Bentivoglio, M., \& Perret, M. (2006). Agerelated effects on the biological clock and its behavioral output in a primate. Chronobiology International, 23, 451-460.

Aujard, F., Dkhissi-Benyahya, O., Fournier, I., Claustrat, B., Schilling, A., Cooper, H. M., \& Perret, M. (2001). Artificially accelerated aging by shortened photoperiod alters early gene expression (FOS) in the suprachiasmatic nucleus and sulfatoxymelatonin excretion in a small primate, Microcebus murinus. Neuroscience, 105, 403-412.

Benloucif, S., Masana, M. I., \& Dubocovich, M. L. (1997). Lightinduced phase shifts of circadian activity rhythms and immediate early gene expression in the suprachiasmatic nucleus are attenuated in old C3H/HeN mice. Brain Research, 747, 34-42.

Benninghoff, J., van der Ven, A., Schloesser, R. J., Moessner, R., Möller, H. J., \& Rujescu, D. (2012). The complex role of the serotonin transport in adult neurogenesis and neuroplasticity. A critical review. The World Journal of Biological Psychiatry, 13(4), 240-247.

Biello, S. M. (2009). Circadian clock resetting in the mouse changes with age. Age, 31, 293-303.

Biello, S. M., Janik, D., \& Mrosovsky, N. (1994). Neuropeptide Y and behaviorally-induced phase-shifts. Neuroscience, 62, 273-279.

Bishop, N. A., Lu, T., \& Yankner, B. A. (2010). Neural mechanisms of ageing and cognitive decline. Nature, 464 (7288), 529-535.

Brock, M. A. (1991). Chronobiology and aging. Journal of the America Geriatrics Society, 39(1), 74-91.

Burwell, R. D., Whealin, J., \& Gallagher, M. (1992). Effects of aging on the diurnal pattern of water intake in rats. Behavioral and Neural Biology, 58(3), 196-203.

Castel, M., \& Morris, J. F. (2000). Morphological heterogeneity of the GABAergic network in the suprachiasmatic nucleus, the brain's circadian pacemaker. Journal of Anatomy, 196(1), 1-13.

Cavalcante, J. S., Alves, A. S., Costa, M. S. M. O., \& Britto, L. R. G. (2002). Differential distribution of afferent containing serotonin and neuropeptide $\mathrm{Y}$ within the marmoset suprachiasmatic nucleus. Brain Research, 927(2), 200-203.

Cavalcante, J. S., Nascimento Júnior, E. S., \& Costa, M. S. M. O. (2006). Componentes centrais do sistema de temporização circadiana: o núcleo supraquiasmático e o folheto intergeniculado. Neurociências, 3, 1-10.

Cayetanot, F., Bentivoglio, M., \& Aujard, F. (2005a). Argininevasopressin and vasointestinal polypeptide rhythms in the 
suprachiasmatic nucleus of the mouse lemur reveal aging-related alterations of circadian pacemaker neurons in a non-human primate. The European Journal of Neuroscience, 22(4), 902-910.

Cayetanot, F., Deprez, J., \& Aujard, F. (2007). Calbindin $\mathrm{D}_{28 \mathrm{~K}}$ protein cells in a primate suprachiasmatic nucleus: localization, daily rhythm and age-related changes. The European Journal of Neuroscience, 26 (7), 2025-2032.

Cayetanot, F., Van Someren, E. J. W., Perret, M., \& Aujard, F. (2005b). Shortened seasonal photoperiodic cycles accelerate aging of the diurnal and circadian locomotor activity rhythms in a primate. Journal of Biological Rhythms, 20(5), 461-469.

Chang, Y. M., Rosene, D. L., Killiany, R. J., Mangiamele, L. A., \& Luebke, J. L. (2005). Increased action potential firing rates of layer $2 / 3$ pyramidal cells in the prefrontal cortex are significantly related to cognitive performance in aged monkeys. Cerebral Cortex, 15(4), 409-418.

Cooke, J. R., \& Ancoli-Israel, S. (2011). Normal and abnormal sleep in the elderly. Handbook of Clinical Neurology, 98, 653-665.

Costa, M. S. M. O., Moreira, L. F., Alones, V., Lu, J., Santee, U. R., Cavalcante, J. S., Moraes, P. R. A., Britto, L. R. G., \& Menaker, M. (1998). Characterization of the circadian system in a brazilian species of monkey (Callithrix jacchus): Immunohistochemical analysis and retinal projections. Biological Rhythm Research, 29(5), 510-520.

Dardente, H., Menet, J. S., Challet, E., Tournier, B. B., Pévet, P., \& Masson-Pévet, M. (2004). Daily and circadian expression of neuropeptides in the suprachiasmatic nuclei of nocturnal and diurnal rodents. Molecular Brain Research, 124, 143-151.

Davidson, A. J., Yamazaki, S., Arble, D. M., Menaker, M., \& Block, G. D. (2008). Resetting of central and peripheral circadian oscillators in aged rats. Neurobiology of Aging, 29(3), 471-477.

de la Iglesia, H. O., Cambras, T., Schwartz, W. J., \& Díez-Noguera, A. (2004). Forced desynchronization of dual circadian oscillators within the rat suprachiasmatic nucleus. Current Biology, 14, 796800 .

de la Iglesia, H. O., Meyer, J., Carpino, A. Jr., \& Schwartz, W. J. (2000). Antiphase oscillation of the left and right suprachiasmatic nuclei. Science, 290(5492), 799-801.

de Vries, M. J., Cardozo, B. N., van der Want, J., Wolf, A., \& Meijer, J. H. (1993). Glutamate immunoreactivity ion terminals of the retinohypothalamic tract of the brown Norwegian rat. Brain Research, 612(1-2), 231-237.

Deelen, J., Beekman, M., Capri, M., Franceschi, C., \& Slagboom, P. E. (2013). Identifying the genomic determinants of aging and longevity in human population studies: progress and challenges. BioEssays, 35(4), 386-396.

Dibner, C., Schibler, U., \& Albrecht, U. (2010). The mammalian circadian timing system: organization and coordination of central and peripheral clocks. Annual Review of Physiology, 72, 517-549.

Dillon, J., Zheng, L., Merriam, J. C., \& Gaillard, E. R. (2004). Transmission of light to the aging human retina: possible implications for age related macular degeneration. Experimental Eye Research, 79, 753-759.

Duan, H., Wearne, S. L., Rocher, A. B., Macedo, A., Morrison, J. H., \& Hof, P. R. (2003). Age-related dendritic and spine changes in corticocortically projecting neurons in macaque monkeys. Cerebral Cortex, 13(9), 950-961.

Duffy, J. F., Willson, H. J., Wang, W., \& Czeisler, C. A. (2009). Healthy older adults better tolerate sleep deprivation than young adults. Journal of the American Geriatrics Society, 57, 1245-1251.

Duffy, J. F., Zeitzer, J. M., \& Czeisler, C. A. (2007). Decreased sensitivity to phase-delaying effects of moderate intensity light in older subjects. Neurobiology of Aging, 28(5), 799-807.

Duncan, M. J, Herron, J. M., \& Hill, S. A. (2001). Aging selectively suppresses vasoactive intestinal peptide messenger RNA expression in the suprachiasmatic nucleus of the Syrian hamster. Molecular Brain Research, 87(2), 196-203.

Duncan, M. J., \& Franklin, K. M. (2007). Expression of the 5-HT7 receptor mRNA in the hamster brain: Effect of aging and association with calbindina-D28K expression. Brain Research, 1143, 70-77.

Duncan, M. J. (2006). Aging of the mammalian circadian timing system: changes in the central pacemaker and its regulation by photic and nonphotic signals. Neuroembryology and Aging, 7, 85-101.
Duncan, M. J., Hester, J. M., Hopper, J. A., \& Franklin, K. M. (2010). The effects of aging and chronic fluoxetine treatment on circadian rhythms and suprachiasmatic nucleus expression of neuropeptide genes and 5-HT1B receptors. European Journal of Neuroscience, 31(9), 1646-1654

Farajnia, S., Michel, S., Deboer, T., VanderLeest, H. T., Houben, T., Rohling, J. H. T., Ramkisoening, A., \& Meijer J. H. (2012). Evidence for neural desynchrony in the aged suprachiasmatic nucleus clock. The Journal of Neuroscience, 32(17), 5891-5899.

Fidalgo, S., Ivanov, D. K., \& Wood, S. H. (2013). Serotonin: from top to bottom. Biogerontology, 14, 21-45.

Fjell, A. M., \& Walhovd, K. B. (2010). Structural brain changes in aging: courses, causes and cognitive consequences. Reviews in the Neurosciences, 21, 187-221.

Garau, C., Aparicio, S., Rial, R. V., Nicolau, M. C., \& Esteban, S. (2006). Age-related changes in circadian rhythms of serotonina synthesis in ring doves: Effects of increased tryptophan ingestion. Experimental Gerontology, 41(1), 40-48.

Gerhold, L. M., Rosewell, L. K., \& Wise, P. M. (2005). Suppression of vasoactive intestinal polypeptide in the suprachiasmatic nucleus leads to aging-like alterations in cAMP rhythms and activation of gonadotropin-releasing hormone neurons. The Journal of Neuroscience, 25(1), 62-67.

Geula, C., Bu, J., Nagykery, N., Scinto, L. F., Chan, J., Joseph, J., Parker. R., \& Wu, C-K. (2003). Loss of calbindina-D28k from aging human cholinergic basal forebrain: relation to neuronal loss. The Journal of Comparative Neurology, 455(2), 249-259.

Gibson, E. M., Williams, III W. P., \& Kriegsfeld, L. J. (2009). Aging in the circadian system: Considerations for health, disease prevention and longevity. Experimental Gerontology, 44(1-2), 51-56.

Glass, J. D., Guinn, J., Kaur, G., \& Francl, J. M. (2010). On the intrinsic regulation of neuropeptide $\mathrm{Y}$ release in the mammalian suprachiasmatic nucleus circadian clock. The European Journal of Neuroscience, 31(6), 1117-1126.

Golombek, D. A., \& Rosenstein, R. E. (2010). Physiology of circadian entrainment. Physiological Reviews, 90(3), 1063-1102.

Hardeland, R. (2012). Melatonin in aging and disease- Multiple consequences of reduced secretion, options and limits of treatment. Aging and Disease, 3(2), 194-225.

Hardeland, R. (2013). Chronobiology of melatonin beyond the feedback to the suprachiasmatic nucleus- consequences to melatonin dysfunction. International Journal of Molecular Sciences, 14, 5817-5841.

Harper, D. G., Stopa, E. G., Kuo-Leblanc, V., Mckee, A. C., Asayama, K., Volicer, L., Kowall, N., \& Satlin, A. (2008). Dorsomedial SCN neuronal subpopulations subserve different functions in human dementia. Brain, 131, 1609-1617.

Hay-Schmidt, A., Vrang, N., Larsen, P. J., \& Mikkelsen, J. D. (2003). Projections from the raphe nuclei to the suprachiasmatic nucleus of the rat. Journal of Chemical Neuroanatomy, 25(4), 293-310.

Hendrickson, A. E., Wagoner, N., \& Cowan, W. M. (1972). An autoradiographic and electron microscopic study of retinohypothalamic connections. Zeitschrift für Zellforschung und Mikroskopische Anatomie, 135(1), 1-26.

Hof, P. R., \& Morrison, J. H. (2004). The aging brain: morphomolecular senescence of cortical circuits. Trends in Neurosciences, 27(10), 607-613.

Hofman, M. A. \& Swaab, D. F. (2006). Living by the clock: the circadian pacemaker in older people. Ageing Research Reviews, 5, 33-51.

Hofman, M. A., Fliers, E., Goudsmith, E., \& Swaab, D. F. (1988). Morphometric analysis of the suprachiasmatic and paraventricular nuclei in the human brain: Sex differences and age-dependent changes. Journal of Anatomy, 160, 127-143.

Huang, Y. L., Liu, R. Y., Wang, Q. S., Someren, E. J. W., Xu, H., \& Zhou, J. N. (2002). Age associated difference in circadian sleepwake and rest-activity rhythms physiology behavioral. Physiology \& Behavior, 76(4-5), 597-603.

Huh, Y., Kim, C., Lee, W., Kim, J., \& Ahn, H. 1997. Age-related changes in the neuropeptide $\mathrm{Y}$ and NADPH-diaphorasepositive neurons in the cerebral cortex and striatum of aged rats. Neuroscience Letters, 223, 157-160. 
Hurd, M. W., \& Ralph, M. R. (1998). The significance of circadian organization for longevity in hamster. Journal of Biological Rhythms, 13(5), 430-436.

Hut, R. A., \& Beersma, D. G. M. (2011). Evolution of time-keeping mechanisms: early emergence and adaptation to photoperiod. Philosophical Transactions of the Royal Society, 366(1574), 21412154

Ingram, C. D., Terenzi, M. G., Howard, H. C., \& Windle, R. J. (1998). Central oxytocin neurotransmission - Receptor characterization and role in modulating limbic circuits in the peripartum period of vasopressin and oxytocin. Advances in Experimental Medicine and Biology, 449, 225-230.

Kalló, I., Kalamatianos, T., Piggins, H. D., \& Coen, C. W. (2004). Ageing and the diurnal expression of mRNAs for vasoactive intestinal peptide and for the VPAC2 and PAC1 receptors in the suprachiasmatic nucleus of male rats. Journal of Neuroendocrinology, 16(9), 758-766.

Kalsbeek, A., Van Heerikhuize, J. J., Wortel, J., \& Buijs, R. M. (1996). A diurnal rhythm of stimulatory input to the hypothalamopituitary-adrenal system as revealed by timed intrahypothalamic administration of the vasopressin V1 antagonist. The Journal of Neuroscience, 16(17), 5555-5565.

Kalsbeek, A., Verhagen, L. A., Schalij, I., Foppen, E., Saboureau, M., Bothorel, B., Buijs, R. M., \& Pevet, P. (2008). Opposite actions of hypothalamic vasopressin on circadian corticosterone rhythm in nocturnal versus diurnal species. The European Journal of Neuroscience, 27(4), 818-827.

Kawakami, F., Okamura, H., Tamada, Y., Maebayashi, Y., Fukui, K., \& Ibata, Y. (1997). Loss of day-night differences in VIP mRNA levels in the suprachiasmatic nucleus of aged rats. Neuroscience Letters, 222(2), 99-102.

Kessel, L., Lundeman, J. H., Herbst, K., Andersen, T. V., \& Larsen, M. (2010). Age-related changes in the transmission properties of the human lens and their relevance to circadian entrainment. Journal of Cataract and Refractive Surgery, 36(2), 308-312.

Kolker, D. E., Fukuyama, H., Huang, D. S., Takahashi, J. S., Horton, T. H., \& Turek, F. W. (2003). Aging alters circadian and lightinduced expression of clock genes in golden hamsters. Journal of Biological Rhythms, 18(2), 159-169.

Krajnak, K., Kashon, M. L., Rosewell, K. L., \& Wise, P. M. (1998). Aging alters the rhythmic expression of vasoactive intestinal polypeptide mRNA but not argenine vasopressin mRNA in the suprachiasmatic nuclei of female rats. The Journal of Neuroscience, 18(12), 4767-4774

Kriegsfeld, L. J., LeSauter, J., \& Silver, R. (2004). Targeted microlesions reveal novel organization of the hamster suprachiasmatic nucleus. The Journal of Neuroscience, 24, 1449-2457.

Kuruba, R., Hattiangady, B., Parihar, V. K., Shuai, B., \& Shetty, A. K. (2011). Differential susceptibility of interneurons expressing neuropeptide $Y$ or Parvalbumin in the aged hippocampus to acute seizure activity. PLoS One, 6(9), e24493.

Lehman, M. N., Silver, R., Gladstone, W. R., Kahn, R. M., Gibson, M., \& Bittman, E. L. (1987). Circadian rhythmicity restored by neural transplant. Immunocytochemical characterization of the graft and its integration with the host brain. The Journal of Neuroscience, 7(6), 1626-1638.

Li, H., \& Satinoff, E. (1998). Fetal tissue containing the suprachiasmatic nucleus restores multiple circadian rhythms in old rats. The American Journal of Physiology, 275(2), 1735-1744.

Liu, J., Head, E., Gharib, A. M., Yuan, W., Ingersoll, R. T., Hagen, T. M., Cotman, C. W., \& Ames, B. N. (2002). Memory loss in old rats is associated with brain mitochondrial decay and RNA/ DNA oxidation: partial reversal by feeding acetyl-L-carnitine and/ or R-alpha -lipoic acid. Proceedings of the National Academy of Science of the United States of America, 99(4), 2356-2361.

Liu, R-Y., Zhou, J-N., Hoogendijk, W. J. G., van Heerikhuize, J. J., Kamphorst, W., Unmehopa, U. A., Hofman, M. A., \& Swaab, D. F. (2000). Decreased vasopressin gene expression in the biological clock of Alzheimer disease patients with and without depression. Journal of Neuropathology and Experimental Neurology, 59(4), 314-322.

Madeira, M. D., Sousa, N., Santer, R. M., Paula-Barbosa, M. M., \& Gundersen, H. J. (1995). Age and sex do not affect the volume, cell numbers, or cell size of the suprachiasmatic nucleus of the rat: an unbiased stereological study. The Journal of Comparative Neurology, 361(4), 585-601.

Mammen, A. P., \& Jagota, A. (2011). Immunocytochemical evidence for different patterns in daily rhythms of VIP and AVP peptides in the suprachiasmatic nucleus of diurnal Funambulus palmarum. Brain Research, 1373, 39-47.

Menna-Barreto, L. \& Díez-Noguera, A. (2011). External temporal organization in biological rhythms. Biological Rhythm Research, 43, 3-14.

Meltzer, C. C., Smith, G., DeKosky, S. T., Pollock, B. G., Mathis, C. A., Moore, R. Y., Kupfer, D. J., \& Reynolds 3rd, C. F. (1998). Serotonin in aging, lete-life depression, and Alzheimer's disease: the emerging role of functional imaging. Neuropsychopharmacology, $18,407-30$

Miller, J. A., Oldham, M. C., \& Geschwind, D. H. (2008). A systems level analysis of transcriptional changes in Alzheimer's disease and normal aging. The Journal of Neuroscience, 28(6), 1410-1420.

Mishima, K., Tozawa, T., Satoh, K., Matsumoto, Y., Hishikawa, Y., \& Okawa, M. (1999). Melatonin secretion rhythm disorders in patients with senile dementia of Alzheimer's type with disturbed sleep-waking. Biological Psychiatry, 45, 417-421.

Monane, M. (1992). Insomnia in the elderly. The Journal of Clinical Psychiatry, (Suppl), 23-28.

Moore, R. Y., \& Eichler, V. B. (1972). Loss of circadian adrenal corticosterone rhythm following suprachiasmatic nucleus lesions in the rat. Brain Research, 42(1), 201-206.

Moore, R. Y., \& Lenn, N. J. (1972). A retinohypothalamic projection in the rat. The Journal of Comparative Neurology, 180(1), 1-14.

Morin, L. P. (1988). Age related changes in hamster circadian period, entrainment, and rhythm splitting. Journal of Biological Rhythms, 3, 237-248.

Morin, L. P. (1999). Serotonin and the regulation of mammalian circadian rhythmicity. Annals of Medicine, 31(1), 12-33.

Morin, L. P. (2007). SCN organization reconsidered. Journal of Biological Rhythms, 22, 3-13.

Morin, L. P. \& Allen, C. N. (2006). The circadian visual system. Brain Research Reviews, 51, 1-60.

Münch, M., Scheuermaier, K. D., Zhang, R., Dunne, S. P., Guzik, A. M., Silva, E. J., Ronda, J. M., \& Duffy, J. F. (2011). Effects on subjective and objective alertness and sleep in response to evening light exposure in older subjects. Behavioural Brain Research, 244, 272-278.

Muller, F. L., Lustgarten, M. S., Jang, Y., Richardson, A., \& Van Remmen, H. (2007). Trends in oxidative aging theories. Free Radical Biology \& Medicine, 43(4), 477-503.

Nakamura, T. J., Nakamura, W., Yamaziki, S., Kudo, T., Cutler, T., Colwell, C. S., \& Block, G. D. (2011). Age-related decline in circadian output. The Journal of Neuroscience, 31(28), 1020110205 .

Nakamura, W., Honma, S., Shirakawa, T., \& Honma, K. (2001). Regional pacemakers composed of multiple oscillator neurons in the rat suprachiasmatic nucleus. The European Journal of Neuroscience, 14, 666-674.

Nygård, M., Hill, R.H., Wikstrom, M. A., \& Kristensson, K. (2005). Age-related changes in electrophysiological properties of the mouse suprachiasmatic nucleus in vitro. Brain Research Bulletin, $65,149-154$

Oh, H., Madison, C., Villeneuve, S., Markley, C., \& Jagust, W. J. (In press). Association of Gray Matter Atrophy with Age, b-Amyloid, and Cognition in Aging. Cerebral Cortex.

Ohayon, M. M., Carskadon, M. A., Guilleminault, C., \& Vitiello, M. V. (2004). Meta-analysis of quantitative sleep parameters from childhood to old age in healthy individuals: Developing normative sleep values across the human lifespan. Sleep, 27(7), 1255-1273.

Olson, E. J., Boeve, B. F., \& Silber, M. H. (2000) Rapid eye movement sleep behaviour disorder: demographic, clinical and laboratory findings in 93 cases. Brain, 123, 331-339.

Palomba, M., Nygård, M., Florenzano, F., Bertini, G., Kristensson, K., \& Bentivoglio, M. (2008). Decline of the presynaptic network, including GABAergic terminals, in the aging suprachiasmatic nucleus of the mouse. Journal of Biological Rhythms, 23(3), 220231.

Park, S. K., Kim, K., Page, G. P., Allison, D. B., Weindruch, R., \& Prolla, T. A. (2009). Gene expression profiling of aging in multiple 
mouse strains: identification of aging biomarkers and impact of dietary antioxidants. Aging Cell, 8, 484-495.

Penev, P. D., Zee, P. C., Wallen, E. P., \& Turek, F. W. (1995). Aging alters the phase-resetting properties of a serotonin agonist on hamster circadian rhythmicity. The American Journal of Physiology, 268 (1pt2), 293-298.

Pereira, P. A., Cardoso, A., \& Paula-Barbosa, M.M. (2005). Nerve growth factor restores the expression of vasopressin and vasoactive intestinal polypeptide in the suprachiasmatic nucleus of aged rats. Brain Research, 1048, 123-130.

Persson, J., Sylvester, C. Y., Nelson, J. K., Welsh, K. M., Jonides, J., \& Reuter-Lorenz, P. Z. (2004). Selection requirements during verb generation: differential recruitment in older and younger adults. NeuroImage, 23(4), 1382-1390.

Piggins, H. D., \& Cutler, D. J. (2003). The roles of vasoactive intestinal polypeptide in the mammalian circadian clock. The Journal of Endocrinology, 177(1), 7-15.

Pinato, L., Frazão, R., Cruz-Rizollo, R. J., Cavalcante, J. S., \& Nogueira, M. I. (2009). Immunocytochemical characterization of the pregeniculate nucleus and distribution of retinal and neuropeptide $\mathrm{Y}$ terminals in the suprachiasmatic nucleus of the Cebus monkey. Journal of Chemical Neuroanatomy, 37(4), 207213.

Pittendrigh, C.S. (1981a). Circadian systems. General perspective. In: Aschoff, J. (ed.), Biological Rhythms (pp. 57-80). Plenum Press, New York-London.

Pittendrigh, C. S. (1981b). Circadian systems. Entrainment. In: Aschoff, J. (ed.), Biological Rhythms (pp. 95-124). Plenum Press, New York-London.

Pontes, A. L. B., Engelberth, R. C. G. J., Nascimento, Jr. E. S., Cavalcante, J. C., Costa, M. S. M. O., Pinato, L., Toledo, C. A. B., \& Cavalcante, J. S. (2010). Serotonin and circadian rhythms. Psychology \& Neuroscience, 2, 217- 228.

Ralph, M. R., Foster, R. G., Davis, F. C., \& Menaker, M. (1990). Transplanted suprachiasmatic nucleus determines circadian period. Science, 247(4945), 975-978.

Reid, K. J., Martinovich, Z., Finkel, S., Statsinger, J., Golden, R., Harter, K., \& Zee, P. C. (2006). Sleep: A Marker of Physical and Mental Health in the Elderly. American Journal of Geriatric Psychiatry, 14, 860-866.

Roberts, D., Killiany, R., \& Rosene, D. (2012). Neuron numbers in the hypothalamus of the normal aging rhesus monkey: stability across the adult life-span and between the sexes. The Journal of Comparative Neurology, 520(6), 1181-1197.

Romijn, H. J., Sluiter, A. A., Pool, C. W., Wortel, J., \& Buijs, R. M. (1996). Differences in colocalization between Fos and PHI, GRP, VIP, and VP in neurons of the rat suprachiasmatic nucleus after a light stimulus during the phase delay versus the phase advance period of the night. The Journal of Comparative Neurology, 372, $1-8$.

Roozendaal, B., Van Gool, W. A., Swaab, D. F., Hoogendijk, J. E., \& Mirmiran, M. (1987). Changes in vasopressin cells of the rat suprachiasmatic nucleus with aging. Brain Research, 409(2), 259264.

Satinoff, E., Li, H., Tcheng, T. K., Liu, C., McArthur, A. J., Medanic, M., \& Gillette, M. U. (1993) . Do the suprachiasmatic nuclei oscillate in old rats as they do in young ones? The American Journal of Physiology, 265(5Pt2), 1216-1222.

Schmidt, C., Peigneux, P., \& Cajochen, C. (2012). Age-related changes in sleep and circadian rhythms: impact on cognitive performance and underlying neuroanatomical networks. Frontiers in Neurology, $3,1-11$.

Shochat, T., Martin, J., Marler, M., \& Ancoli-Israel, S. (2000). Illumination levels in nursing home patients: Effects on sleep and activity rhythms. Journal of Sleep Research, 9(4), 373-380.

Silver, R., \& Schwartz, W. J. (2005). The suprachiasmatic nucleus is a functionally heterogeneous timekeeping organ. Methods in Enzymology, 393, 451-65.

Silver. R., Romero, M-T., Besmer, H. R., Leak, R., Nunez, J. M., \& LeSauter, J. (1996). Calbindin-D28k cells in the hamster SCN express light-induced Fos. Neuroreport, 7(6), 1224-1228.

Singletary, K. G., \& Naidoo, N. (2011). Disease and degeneration of aging neural systems that integrate sleep drive and circadian oscillations. Frontiers in Neurology, 2, 1-8.
Swaab, D. F., Flies, E., \& Fisser, B. (1985). The vasopressin containing neurons in the human brain: changes during ageing and senile dementia. British Journal of Clinical Practice, Supplement, $39,7-10$.

Tanaka, M., Ichitani, Y., Okamura, H., Tanaka, Y., \& Ibata, Y. (1993). The direct retinal projection to VIP neuronal elements in the rat SCN. Brain Research Bulletin, 31, 637-640.

Tanaka, M., Yamaguchi, Takahashi M., Hashimura, K., Shibata, T., Nakamura, W., \& Nakamura, T. J. (2012). Effects of age-related dopaminergic neuron loss in the substancia nigra on the circadian rhythms of locomotor activity in mice. Neuroscience Research, 74(3-4), 210-215.

Tomasy, D., \& Volkow, N. D. (2012). Aging and functional networs. Molecular Psychiatry, 17, 549-558.

Tractenberg, R. E., Singer, C. M., \& Kaye, J. A. (2005). Symptoms of sleep disturbance in persons with Alzheimer's disease and the normal elderly. Journal of Sleep Research, 14, 177-85.

Tricoire, H., Locatelli, A., Chemineau, P., \& Malpaux, B. (2002). Melatonin enters the cerebrospinal fluid through the pineal recess. Endocrinology, 143, 84-90.

Tsukahara, S., Tanaka, S., Ishida, K., Hoshi, N., \& Kitagawa, H. (2005). Age-related change and its sex diferences in histoarchitecture of hypothalamic suprachiasmatic nucleus of $\mathrm{F} 344 / \mathrm{N}$ rats. Experimental Gerontology, 40(3), 147-155.

Ukai, H., \& Ueda, H. R. (2010). Systems biology of mammalian circadian clock. Annual Review of Physiology, 72, 579-603.

Valentinuzzi, V. S., Scarbrough, K., Takahashi, J. S., \& Turek, F. W. (1997). Effects of aging on the circadian rhythm of wheel running activity in C57BL/6 mice. The American Journal of Physiology, 273(6 Pt2), 1957-1964.

Van den Pol,A. N. (1991). The suprachiasmatic nucleus: morphological and cytochemical substrates for cellular interaction. In: D. C. Klein, R. Y. Moore \& S. M. Reppert (Eds.), Suprachiasmatic nucleus: the mind's clock (p.17-50). New York: Oxford University Press.

Van Reeth, O., Zhang, Y., Reddy, A., Zee, P., \& Turek, F. W. (1993). Aging alters the entraining effects of an activity-inducing stimulus on the circadian clock. Brain Research, 607(1-2), 286-292.

Veyrat-Durebex, C., Quirion,. R., Ferland, G., Dumont, Y., \& Gaudreau, P. (2013). Aging and long-term caloric restriction regulate neuropeptide Y receptor subtype in the rat. Neuropeptides, 47(3), 163-169.

Watanabe, A., Shibata, S. \& Watanabe, S. (1995). Circadian rhythm of spontaneous neuronal activity in the suprachiasmatic nucleus of old hamster in vitro. Brain Research, 695(2), 237-239.

Weinert, D. (2010). Circadian temperature variation and ageing. Ageing Research Reviews, 9(1), 51-60.

Weinert, H., \& Weinert, D. (1998). Circadian activity rhythms of laboratory mice during the last weeks of their life. Biological Rhythm Research, 29(2), 159-178.

Welsh, D. K., Logothetis, D. E., Meister, M., \& Reppert, S. M. (1995). Individual neurons dissociated from rat suprachiasmatic nucleus express independently phased circadian firing rhythms. Neuron, 14, 697-706

Welsh, D. K., Takahashi, J. S., \& Kay, S. A. (2010). Suprachiasmatic nucleus: Cell autonomy and network properties. Annual Reviews of Physiology, 72, 551-577.

Witting, W., Mirmiran, M., Bos, N. P. A., \& Swaab, D. F. (1993). Effect of light intensity on diurnal sleep-wake distribution in young and old rats. Brain Research Bulletin, 30(1-2), 157-162.

Wolkove, N., Elkholy, O., Baltzan, M., \& Palayew, M. (2007). Sleep and aging: 1. Sleep disorders commonly found in older people. Canadian Medical Association Journal, 176(9), 1299-1304.

Xu, J., Gu, C., Pumir, A., Garnier, N., \& Liu, Z. (2012). Entrainment of the suprachiasmatic nucleus network by a light-dark cicle. Physical Review, 86(4 Pt 1), 1-5.

Yamazaki, S., Straume, M., Tei, H., Sakaki, Y., Menaker, M., \& Block, G. D. (2002). Effects of aging on central and peripheral mammalian clocks. Proceedings of the National Academy of Sciences of the United States of America, 99(16), 10801-10806.

Yannielli, P. C., \& Harrington, M. E. (2004). Let there be "more" light: enhancement of light actions on the circadian system through non-photic pathways. Progress in Neurobiology, 74, 59-76.

Zhang, Y., Brainard, G. C., Zee, P. C., Pinto, L. H., Takahashi, J. S., \& Turek, F. W. (1998). Effects of aging on lens transmittance and 
retinal input to the suprachiasmatic nucleus in golden hamsters. Neuroscience Letters, 258(3), 167-170.

Zhang, Y., Kornhauser, J. M., Zee, P. C., Mayo, K. E., Takahashi, J. S., \& Turek, F. W. (1996). Effects of aging on light-induced phaseshifting of circadian behavioral rhythms, FOS expression and CREB phosphorylation in the hamster suprachiasmatic nucleus. Neuroscience, 70, 951-61.

Zhdanova, I. V., Masuda, K., Quasarano-Kourkoulis, C., Rosene, D. L., Killiany, R. J., \& Wang, S. (2011). Aging of intrinsic circadian rhythms and sleep in a diurnal nonhuman primate, Macaca mulata. Journal of Biological Rhythms, 26(2), 149-159.

Zhou J-N, Riemersma, R. F., Unmehopa, U. A., Hoogendijk, W. J. G., van Heerikhuize, J.J., Hofman, M. A., \& Swaab, D. F. (2001). Alterations in argenine vasopressin neurons in the suprachiasmatic nucleus in depression. Archives of General Psychiatry, 58(7), 655-662.

Zhou, J-N., \& Swaab, D. F. (1999). Activation and degeneration during aging: A morphometric study of the human hypothalamus. Microscopy Research and Technique, 44(1), 36-48. 